\title{
Schooling Spaces of African Migrant Children: Vulnerability, Agency and Resiliency
}

\author{
Nithi Muthukrishna \\ ORCID iD: https://orcid.org/0000-0003-1784-1124
}

\author{
Kubendri Maduray \\ ORCID iD: https://orcid.org/0000-0002-1252-4261
}

Susan Philpott

ORCID iD: https://orcid.org/0000-0002-7934-1435

\begin{abstract}
The aim of the research presented in this article was to delve into the schooling experiences of African migrant children in the province of KwaZulu-Natal, South Africa. The study was conducted at a secondary school situated in the greater Durban metropolitan region that is known to have a significant African migrant child population. The participants were seven African migrant learners aged from 15-18 years, in grades 11 and 12. Data were generated through individual interviews, focus group interviews and the participatory method of photovoice. The findings revealed that African migrant students were able to actively evaluate and construct meanings around their experiences within schooling spaces, and were active agents in the construction and negotiation of their own spatialities. Students viewed their cultural and social capital as an advantage in their social lives and in achieving academic goals. Networks of support were formed to create a positive schooling experience. These relationships were rich sources of social capital. While vulnerabilities such as human rights violations, discrimination, social alienation and exclusion were manifest, particularly from their South African peers, participants successfully navigated these and were able to create spatialities in which they could build their agency, resiliency and social power.
\end{abstract}

Keywords: migrant learners in South Africa, resiliency, vulnerability, oppression, agency, children's geographies, narrative inquiry, photo-voice 


\section{Introduction}

In recent years, with the global movement of people across borders increasing dramatically due to forced and voluntary migration, a major area of research interest to international scholars has been to explore the educational experiences of immigrant students in the host countries (for example, McGovern \& Devine 2015; Crul et al. 2017; Dryden-Peterson 2017). There is a limited but growing body of recent research on the schooling experiences of immigrant learners emanating from sub-Saharan Africa (Chigeza et al. 2013; Meda 2017; Daniels 2018; Isseri et al. 2018). The study presented in this article sought to engage in a critical analysis of immigrant learners' experiences of schooling in the South African context, and to advance academic knowledge on this subject.

The White Paper on International Migration (Republic of South Africa 1999) declares that immigrants are persons who migrate across borders to change their place of residence. Immigrant populations are extremely heterogeneous in different countries, and may include refugees and asylumseekers. The 1951 Geneva Refugee Convention defines a 'refugee' as a person who is outside their country of origin or habitual residence because they have suffered (or fear) persecution on account of race, religion, nationality, political opinion or because they are a member of a persecuted social group (UN General Assembly 1951). An 'asylum-seeker', on the other hand, is a person who has made a claim for recognition as a refugee, and who is waiting for a decision to be made (Amnesty International 2019). For the purpose of this study, 'immigrant learners' were defined as those from other countries, foreign nations who have migrated across the border to settle in South Africa and are now learners in South African schools. In examining literature emanating from sub-Saharan Africa, we have noted that scholars advocate for use of the concept 'African migrant' (Adebayo 2010; Nnadozie 2010). This phrase collectively encompasses the broad category of refugees, asylum seekers and voluntary immigrants who have in common that they are foreign and from elsewhere in Africa; whether or not they have applied for citizenship or they are legally in the country (Nnadozie 2010). This is the concept and conceptualisation we have used in this research.

\section{Immigration Policy and Legislative Frameworks in South Africa}

Since the advent of democracy in 1994, the South African government has 
sought to address the restrictive immigration laws of the apartheid state. Changes were made in formulating immigrant laws and policies that were compatible with the South African Constitution of 1996, the key principles of which uphold basic human rights, including the right to life, freedom, dignity and education. The Refugees Act (Republic of South Africa 1998) states that a refugee 'enjoys full legal protection, which includes the rights set out in Chapter Two of the South African Constitution (Republic of South Africa 1996), and the right to remain in the Republic in accordance with the provisions of this Act' (Republic of South Africa 1998:8). The Immigration Act, No. 13 of 2002 (Republic of South Africa 2002) and the Immigration Amendment, Act No. 19 of 2004 (Republic of South Africa 2004) consolidated the new system of immigration control which ensures that temporary and permanent residence permits are issued as expeditiously as possible. The Immigration Act legislates that immigration control is performed within the highest applicable standards of human rights protection and that xenophobia is countered within both government and civil society (Republic of South Africa 2002). As a result, entry into the country has become easier and immigrants are provided with opportunities to become citizens of the country in a manner that protects their basic human rights. Additionally, with the new legislation, South Africa accorded three amnesties for undocumented Southern African Development Community (SADC) migrants between 1996 and 2002 (Van Lennep 2019). These amnesties were for various categories of African migrants who had entered the country illegally or who had no rights to remain in the country, giving them rights to permanent residence or citizenship; they enabled the migrants to consider remaining in South Africa with their families, including their children (Hemson 2011).

\section{Immigrant Children in South African Schooling Contexts}

In many schooling contexts internationally, immigrant children and young people continue to experience academic, social and cultural barriers and structural inequalities that are likely to shape their future life chances (Moskal 2014; Mendenhal et al. 2017. Studies show that migrant children often face conflict with regard to maintaining their culture (Vandeyar \& Vandeyar 2011); they find it difficult to successfully integrate into the new socio-cultural environment (Dryden-Peterson 2017; Darmody et al. 2013), and creating and maintaining a sense of identity is a struggle for those from different religious, 
cultural and ethnic backgrounds (Nnadozie 2010; Moskal 2014).

In the South African context, research has shown that for immigrant children, access to quality education is a key challenge. There are two kinds of barriers to accessing education: hindrances to registering in a school, and barriers related to migrant learners maintaining and supporting themselves once in school (Crush \& Tawodzera 2011; Isseri et al. 2018). A study by Vandeyar and Vandeyar (2011) found that black female migrant students battled to build and navigate their identities and to develop into self-assured individuals.

Research by Adebayo (2010) highlighted the complex ways in which immigrant youth try to hold onto value systems that they had inherited from their respective countries of origin while simultaneously attempting to find a niche and acceptance in the host country. Studies have indicated that xenophobia is a serious challenge to educational contexts in South Africa (Crush \& Tawodzera 2011; Vandeyar \& Vandeyar 2011), and that young immigrants often find it difficult to overcome the racism and discrimination perpetrated against them by local students.

Language is a key aspect of social integration and one that fosters empowerment. Within the school context, children utilise language to share ideas, build relationships, and communicate with peers and teachers (Asanova 2005). A difference in language is often the first hindrance that many immigrants encounter when crossing borders (Hlatshwayo \& Vally 2014; Kamuangu 2007). While South Africa is considered a multilingual nation, English is the dominant language and the most commonly used in media, education, industry, commerce, etc. It is the medium through which almost all teaching and learning is done.

While the struggles of immigrants and their children in the host country are well documented in both local and international literature, interwoven in research is evidence of the perseverance, resilience and agency of migrant children. It is important to note that there are migrant children who rise above negative experiences (Isseri et al. 2018). A few studies have foregrounded that children of migrants emerge as highly motivated to succeed largely because migrants have the aspiration to improve their economic or social circumstances in the host country, and this type of attitude is transferred to their children (Hemson 2011; Hlatshwayo \& Vally 2014). As a result of this motivation, academically, African migrant scholars have been shown to significantly outperform local students in many schooling contexts (Hemson 2011; Isseri et al. 2018). 
The aim of the study presented in this article was to investigate the schooling experiences of African migrant children in their respective school contexts and intersecting settings. The following research questions were explored: What stories do African migrant children have to tell about their schooling experiences in South Africa? What are the inclusionary processes and exclusionary pressures that impact the lives of African migrant children? How do African migrant children navigate exclusionary pressures?

\section{Research Methodology and Design Methodological Issues}

The study was qualitative in nature as the aim was to uncover, interpret and portray particular social realities in context from the perspective of the participants under study (Denzin \& Lincoln 2005). Human beings are viewed as meaning-making actors in their everyday lives. The assumption is that there exists a dynamic and negotiated social reality as people act and bring meanings to it. The research tradition was narrative inquiry, which is a way of inquiring into, studying and making sense of experience that is understood narratively. Narrative inquiry is underpinned by the view that human beings lead storied lives (Bell 2008; Clandinin et al. 2007). People shape their daily lives by stories of who they are and who others are. Further, individuals interpret their past in terms of these stories. The telling and retelling of stories enables the participants to envision their own stories (Connelly \& Clandinin 1990; Clandinin et al. 2007). Narratives are holistic and encompass all facets of humanity: the emotional, physical, social and cultural aspects of life.

The concept of 'children's geographies' framed the study. In recent years, geographers have been charting the experiences and practices of young people empirically, as children offer a lens through which to understand a range of issues in their lives (Jeffery 2010). Children's geographies, a sub-field of study in human geography, examines the places and spaces of children's lives in all their intricacy. In our study, we drew on the work of Seamon and Sowers (2008) in our conceptualisation of the notions of space and place. Seamon and Sowers (2008), in their paper, elucidate the work of Edward Relph, the renowned Canadian geographer. We define 'place' as a location crafted by human experiences such as a classroom, a school, a city and a neighbourhood. The same place can be experienced differently by different individuals (e.g. an old student at a school; a newcomer to the school). Further, over time an 
individual can experience the same place differently at different times (e.g. a classroom with a new teacher; the home when a parent dies).

We view the notion of space as somewhat abstract, for example, a space of safety; a space of vulnerability; spaces of agency; a space of freedom. The conception or understanding of space is associated with and connected to the places we occupy. Spaces gain meaning from their spatial context and what occurs in them. Space has many different lived dimensions of experience. The key quality of any place is that it has the power to order, direct and to centre the intentions, meanings, experiences and actions of human beings spatially. Spatiality is thus situated and localised in one sense, and in another sense, it is carried within the body and mind as memories and lived experiences from the past, and ideas about the future (Cele 2006). Van Ingen and Halas (2006: 382) assert that schools are 'richly textured, power laden spatialities of everyday life'. Van der Burgt (2015) suggests that the arrangement of places where children are active is often constructed by adults. Yet, children's spatialities are indeed also created by themselves within these places. They are not passive in the face of spatial constraints but have agency in the production of space.

The sub-field of children's geographies is associated with an area of scholarship referred to as New Childhood Studies (Holloway \& Valentine 2000). Childhood is seen as a compilation of negotiated social relationships, where children are active agents in the construction of their own social world, interpreting the meaning of that world and its significant influences in their lives. James and Prout (1997) argued that childhood is a distinct and interesting phase in human experience and that children are fully formed and complete individuals with perspectives of their own. New Childhood Studies influenced our ontological and epistemological stance on children and childhood in the study. We conceptualise children as social beings in their own right. We conceived all truth to be constructed by individuals within certain moments, experiences and in different contexts (De Gialdino 2009). As such, multiple meanings can exist within the data generated in a study. Our perspective is that children are actively able to construct their own meanings of their experiences in schools; hence, valuable insider knowledge can be gained from the child participants (De Gialdino 2009).

\section{Research Design}

The study was conducted at a secondary school situated in the province of 
KwaZulu-Natal that has a significant immigrant student population. In the first phase of sampling, purposive sampling was used, as foreign nationality was identified as the defining characteristic of the participants to be selected. In addition, the sample was restricted to grade 11 and 12 learners. In the second phase, from the pool of learners who volunteered to participate in the study and from whom consent was attained, seven learners were selected. The age range was from 15-18 years of age. Four learners were from Zimbabwe; two from Malawi, and one from Swaziland. The learners had been in South Africa for about two to seven years.

Data generation involved individual narrative interviews and focus group interviews. In both the focus group and individual interviews, the interview question was: I am interested in hearing the story of your schooling experiences in South Africa. Please tell me your story? The advantage of employing the narrative interview is that it enables the researcher to probe and gain clarity on issues regarding the phenomenon being investigated (Wengraf 2006). The minimal direction exerted allows the participants to express their subjective stories as fully and as spontaneously as they are able (Fontana \& Frey 2003). The aim was to ensure a rich collection of descriptive narratives. All interviews were conducted in English, recorded digitally and later transcribed verbatim.

An innovative aspect of the study was the use of visual methodology viz. photographs as a tool for gathering information during the interviews. The method uses photography, a participatory research tool, in order to tell and visually document a story (Jacobs \& Harley 2008; Morojele \& Muthukrishna 2012). This data generation tool has been used in studies internationally, in researching various issues with children, for example, bullying (Newman et al. 2006); the lives of refugee children (Gifford et al. 2007); and children communicating their experiences of place and spaces in their lives (Cele 2006; Morojele \& Muthukrishna 2012). The photovoice process has been described by various researchers whose work informed our process (for example, Jacobs \& Harley 2008; Morojele \& Muthukrishna 2012). Photovoice engages the participants in capturing and representing their schooling experiences through a series of photo images. In the study, participants were provided with disposable cameras and requested to take photos that would convey the story of significant schooling spaces. The photovoice method and process used is outlined in Maduray (2015). Photovoice generated photo narratives.

Ethical clearance for the project was obtained from the University of 
KwaZulu-Natal through its research office. Prior to the commencement of the data collection process of the study, permission to conduct the study was obtained from the Provincial Department of Education, and the principal of the school. Informed consent was attained from all participants, and from parents of the participants, since the children were legally minors. Every step in the research was taken with the informed consent of the participants, for example, audio-recording the interviews, the use of photovoice and the ethical issues related to the process. The participants, their parents and the principal of the school were assured that appropriate measures would be taken to ensure confidentiality and anonymity of the school and the participants. In this article, pseudonyms are used to protect their identity of the participants.

In the data analysis process, our aim was to represent the learners' stories in a coherent and meaningful manner. It is conceded that children's narratives would be dependent on the context of the narrator and the listener; and are not intended to denote 'truth' (Hunter 2010). Data analysis involved reading the interview at least three times, once to get a sense of the entire story, and then listening for the 'first person' voice, and other significant voices.

In the first phase of data analysis, the photographs and the related photo-narratives were collated, examined and analysed. The following questions guided reflections: What do we see in the photographs? How does the image relate to context? How does it relate to the participants' schooling spaces? What is said? What is left unsaid? How does the photo narrative link with the particular visual representation?

In the second phase, the texts from the photo-narratives and the interviews were read and re-read several times to gain multi-layered insights into how they depicted participants' schooling spaces and places. Data analysis was inductive in nature: guided by the research questions, drawing on the literature review and theory to explain and understand the intricacies of schooling spaces and experiences, and finally identifying categories of meaning, patterns and themes. The study was conducted in 2015, over a threemonth period.

\section{Discussion of Findings}

The learners' voices illuminated the spaces and spatial conditions within the schooling context that shaped their lives, and the processes that maintained or challenged spatial conditions for migrant learners. In this section, we focus on 
three themes: Social spaces of exclusion, oppression and vulnerability; Spaces of opportunity, agency and resiliency; and Spaces of inclusion, care and belonging. Through these themes, we examine the complex and multifaceted schooling experiences of the migrant learners in South Africa. We also seek to uncover the exclusionary pressures that impact the children's lives, and how they navigate exclusion and oppression. Finally, we illuminate encounters of inclusion and agency in the schooling spaces. In the discussion below, data from the individual interviews, focus group interviews and the photo-narratives are integrated.

\section{Social Spaces of Exclusion, Oppression and Vulnerability}

There has been a spate of xenophobic attacks on foreigners in South Africa since about 2008 (Chigeza et al. 2013; Ngcamu \& Mantzaris 2019). Studies have found that migrant learners entering the school environment are subjected to human rights violations, exclusions based on stereotypical behaviours and often face a long struggle towards gaining acceptance (Kruger \& Osman 2010; Hlatshwayo \& Vally 2014). Through the narratives of the learners, our study exposed spaces and places in the schooling context where they had experienced discrimination, prejudice and vulnerability. It is significant that none of the participants told of teachers being perpetrators of discrimination and prejudice. The stories portrayed teachers as being caring, supportive and empathetic.

Ian took a photo of the school playground. He explained the reason for the focus on this space in his photo-narrative below.

I took this because of an incident that happened. A boy just ran over and slapped me. I had no reason as to why he would do that .... I mean I never really communicated with the boy before ... maybe it was some sort of dare but it happened a long time ago and as I have said, I have adapted to survive (Ian, 17 years old, Malawi) (Photo narrative).

Ian went on to state:

Some South African students ... not all ... kind of like a couple, two or three, but you know they make the comments and the whole class starts laughing, you are excluded of [from it] all but anyway I had to get over it .... I had to adapt to survive. I was a little bit older than my 
sister, so I thought, 'If I could be that depressed how much would my sister be now?' Numerous people have called my sister and me 'kwerekwere' countless number[s] of times .... I respond by walking away.... (Photo narrative).

Alice, 15 years old, from Malawi took photographs of the school corridors, hallways and stairways. In her photo narrative she explained the reason.

These are photos of the hallways and staircases at school. Sometimes we were passing to go [to] class, other children will mock us in their language that we can't understand or call us names and things. But you can't really do anything...you just have to go and sit there and pretend that you didn't hear anything because things might get bad if you respond to them, like a fight or something (Alice, 15 years old, Malawi) (Photo narrative).

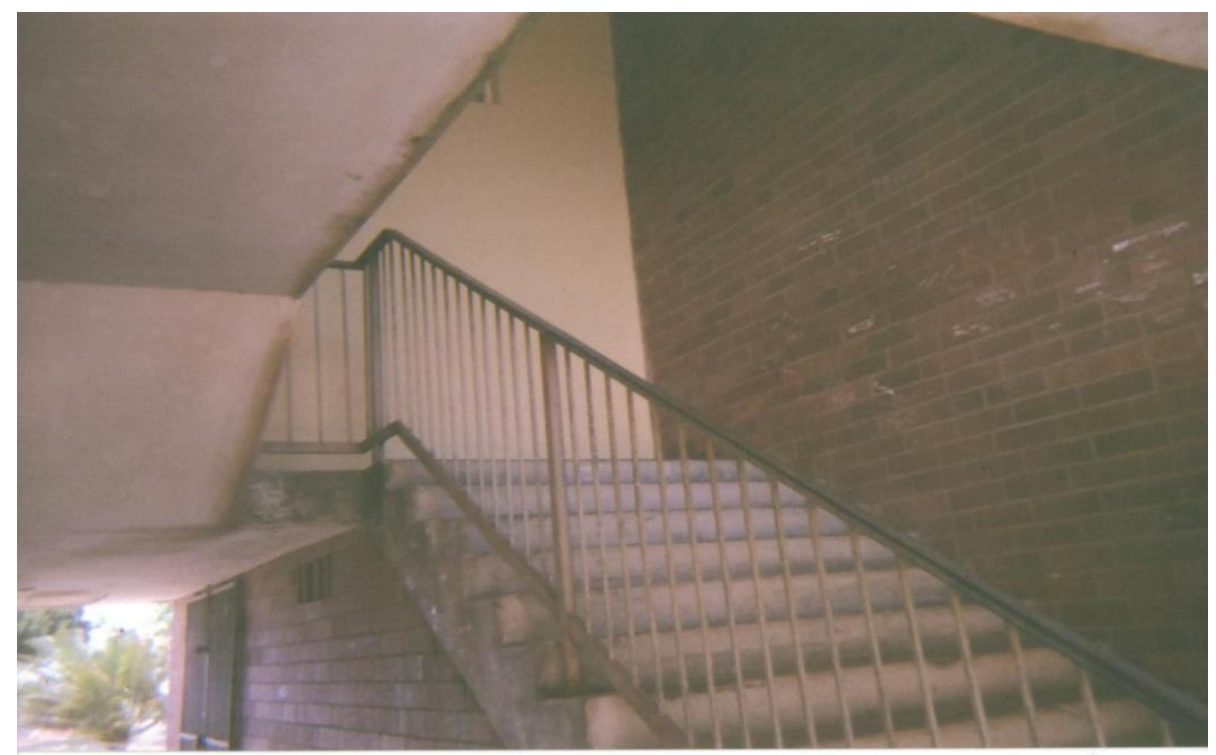

Figure 1: The school stairway

The narratives exposed the bullying and reflected overtones of xenophobia 
faced by many African migrants within the school at which the study was conducted, which is also evident in studies across South African schools (Adebayo 2010; Nnadozie 2010; Osman 2009). Participants were subjected to derogatory taunts and name-calling and, in one instance, unprovoked physical abuse. The term 'kwerekwere', a South African slang term, is derogatory and directed at foreigners. The narratives reflected spaces in which these migrant students felt unsafe and vulnerable.

Magnus from Zimbabwe, explained his photograph of the school toilets, a space in which migrant learners were most at risk of being victims of crime.

This is place where a lot of the international students, especially myself never go. It's a place where we could get and have been robbed, and so we actually stay away from there. We make sure, no matter what, we don't need to go to the toilet the whole day. If matters are urgent and we do need to go, then we leave all our valuables with someone we trust or with a teacher and try and go in between class times rather than on our break time or lunch (Magnus, 17 years old, Zimbabwe) (Photo narrative).

A contributing factor to any individual feeling a sense of exclusion in a society is encountering a language barrier where one is unable to grasp the meaning of, and engage in conversation with peers. For numerous young migrants, experiencing language as a barrier is common, especially when entering the school system (Asanova 2005; Yu \& Shandu 2017). In the majority of schools in South Africa, English is the medium of instruction. However, indigenous South African languages are often spoken both in and out of the classrooms at a social level. In the narratives that emanated from the study, it was evident that young African migrants have felt a sense of isolation, vulnerability and exclusion related to the language issue in their early years in the country. However, these experiences related largely to the use of the vernacular language, isiZulu, in social spaces. This is evident in the narratives below.

Well... when I first came to school... there would be people who are talking their language, they would be associating with themselves, because they spoke their own languages. They would say ... like, 'We 
speak Zulu and we can't do anything about it.' So there was nothing really that I could [do] so I just kept quiet and sat there because I didn't know the language.

I was lonely .... I just .... I thought maybe they were saying something about me .... they were mocking me .... So ... most of the times I just stayed alone because they would be talking and talking and talking, and I just feel [felt] left out from there. So it was bad. And that still happens now and again ... so I just seclude myself and take a novel and read or write something down ... I don't know ... anything that helps me feel like ... I feel I'm in the book ... I'm part of something. (Alice, 15 years old, Malawi) (individual interview).

It was hard for me to reply to them in Zulu so when they would talk to me I would respond in English. And you find that some of them don't understand English so they would think that you are teasing them or swearing [at] them because they don't understand you. And they will start calling you names like 'foreigner'. It even happened in the Zulu class. That's why I gave up Zulu anyway. I took Afrikaans...in that class ... it was like there were Indians there most of them, they didn't understand Afrikaans as well ... so we were all like the same. (Yasmine, 17 years old, Zimbabwe) (Individual interview).

The narratives revealed spaces of social alienation arising from the language issue. Yasmine opted for curriculum change in that she dropped isiZulu from her curriculum and switched to Afrikaans as the first additional language. She made this decision to avoid the discriminatory taunts she had experienced in the isiZulu class. She found the Afrikaans class to be a safer social space. Alice poignantly explains how she sought refuge in books and how she felt that she was 'in the book' and 'felt part of something' through her book. Holloway and Valentine (2000) would argue that the participants were adept at interpreting the meaning of social spaces and recognising that in order to achieve predetermined goals, they would need to make significant changes. This displays that they were active agents in the negotiation of their schooling spatialities.

In the interviews, participants shared their assumptions about the key sources of discriminatory attitudes of local students. In the view of Yasmine, 
17 years old, from Zimbabwe, there were oppressive myths that circulated in the schooling context. She provided this insight,

I think that when the teachers praise us...the bad thing is that ... especially when you work hard, right, and teachers are proud of you. It's like ... because you are not from this country, the other students are like .... 'Oh you['re] using something to get there...like you['re] using something like...what do you call it? Muti or witchcraft or something'. You know they say ... you know it's like those Nigerian movies that they watch so they think that we Zimbabwean people...oh we come from Nigeria and that's what they think. So watching from these movies, they see all this witchcraft happening there and they say, 'Oh no, that's what you['re] using to do well or that's what you['re] using to get good marks .... that's why all the teachers like you ....and you don't get into trouble' (Yasmine, 17 years old, Zimbabwe) (individual interview).

In the focus group interview, Thomas from Zimbabwe, added his analysis stating that local students were resentful of high performing migrant students.

But I think the real problem with that is that they are like the top two students in the school. Ja ... and everybody in the school thinks so...the jealousy...so I think that plays a part in the discrimination. (Thomas,

17 years old, Zimbabwe) (Focus group interview).

A dynamic that emerged during conversations with the participants was that 'local' students would often disparage the achievements of the migrant group. Migrant scholars' accomplishments were often attributed to external forces such as the practice of witchcraft and to favouritism on the part of the teachers.

\section{Spaces of Opportunity, Agency and Resiliency}

In the study it was evident that within the schooling context there were spaces of unequal power relations that produced complex vulnerabilities. However, migrant learners' agency and resiliency and their determination to subvert vulnerability was also evident. Literature has shown that the main reason for the increase in the influx of migrants into South Africa is the opportunities that 
are available to these migrants (Hemson 2011; Vandeyar 2012). All participants in the study clearly saw education as their greatest opportunity to achieve a successful and productive life in South Africa. These sentiments are echoed by Amanda, 18 years old, from Zimbabwe, who took this photograph which she titled, 'freedom'. Her photo-narrative is below.

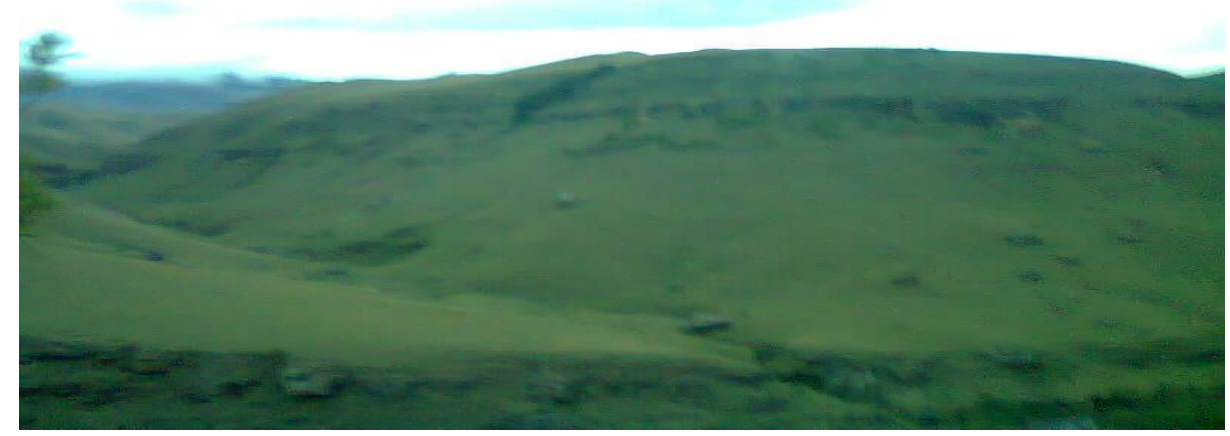

Figure 2: Freedom

This photograph in a way represents how I feel about South Africa and going to school and living here. We have so much [many] things we can do here. Everything is more advanced .... you know when I was in Zimbabwe, my parents and I didn't even think that I was going to get a phone, I didn't even think that I was going to get to have my hair done, and do all that kind of stuff. I'm starting my life in SA...getting an education, I want to go to university and then find a good job here. I wouldn't want to go back .... I would go to visit but I'm starting my life here, I'm doing my education here and studying here, I am happy (Photo narrative).

Similarly, Gwen, 17 years old, from Swaziland agreed, 
... Well there are so many opportunities in this country. Like we can go to school, finish school and go to university and stuff. Getting good jobs and things (Focus group interview).

Despite the view that they valued education in South Africa as reflected in the narratives of Amanda and Gwen, there were participants who were disparaging of the quality of education in South Africa. They were critical of the low percentages set for a pass in subjects within the school curriculum. Gwen explained,

When I came here, I found that the passing rate is $30 \%$ for certain subjects. So umm.. at school when you find that you have to know $30 \%$ of the work ....it was a ridiculous amount. So here we [are] just thinking, 'Okay phew! ....as long as I get 30\%, it's okay'. It is much lower than what [the pass mark] was at home in Swaziland (Individual interview).

Gwen recounted how she chose to reclaim her academic space through her own agency, 'So I just make my own passing rate .... I say $50 \%$... so I do that'.

Magnus from Zimbabwe, had this to say:

Prior to coming to SA, my schooling experiences...how can I explain it? ... it was actually more intense. It was like more than 8 hours of school ... ja, more like that. So it was very, very intense, and I actually think that it was better. When I first came to South Africa, my concentration in the classroom was very high because I was used to a full day (Individual interview).

Similarly, Thomas in his narrative below reflected on his experience of schooling on arrival in South Africa, and on how he negotiated aspects of what he believed to be limitations within the education system.

I have been in SA for seven years and the education here is very different. In Zimbabwe, the education is difficult...some people could say that it's actually harder there than in South Africa. So, my everyday life I know that what I used to do there is harder than in this country, so I work harder because I know I have an advantage over 
here. So, it pushes me to go higher (Individual interview).

Thomas's assessment of the low standard of education in South Africa served to enhance his drive and determination to achieve at high levels academically. All the participants commented about a lack of a sense of responsibility and commitment to their studies and levels of engagement on the part of local students. Yasmine from Zimbabwe narrated,

... I think that coming from another country like ... it makes you focused because you know what you want and you know what you are here for, and that is education, and you are focused. Being with other children here, you learn that other children are not focused and are doing all the wrong things. And instead of doing that and later regretting [it], you learn from their mistakes (Individual interview).

The above narratives reveal that the migrant learners are active agents in the construction and negotiation of their schooling spatialities. Their agency is evident in the way they explain how they navigate spaces in the system that they believe to be problematic. They strive to maintain high levels of commitment to their studies, and a rigorous regime of focus, concentration and motivation that they were socialised into by the ethos and culture of schools in their native countries.

While research has documented the difficulties and struggles of migrant students in the schooling contexts (Nnadozie 2010; Osman 2009; Vandeyar \& Vandeyar 2011), other studies have shown that many migrant scholars have resilient mind-sets that drive them towards success (Hemson 2011; Nnadozie 2010; Suárez-Orozco et al. 2009). The students in this study were no different. Within the group interviewed, three were high performers and amongst the top five students in their grade. The participants were not only academically inclined but two of them excelled in sport, representing their school at inter-school level. Most of the young students were involved with various community projects, including recycling and other charitable initiatives. Some of the participants viewed engaging in projects such as toy drives at the local church and providing tutoring services to their peers as their contributions to their school and to immigrant communities.

In trying to make sense of the participants' ways of negotiating their schooling spaces above, we drew on the work of French sociologist, Pierre 
Bourdieu. Bourdieu would refer to what these participants bring to their schooling experiences in South Africa as a form of cultural capital - ways of talking, engaging and socialising, as well as beliefs, values and behaviour patterns. These behaviours would be considered embodied capital in the view of Bourdieu (Bourdieu \& Passeron 1977). Although his theory was class related, in that cultural capital was seen as symbols and meanings reproduced by the dominant middle class, in our study it became evident that the participants were able to reproduce socialised behaviours that were valuable assets to their educational success in South Africa, and to making the most of opportunities that lay before them. Bourdieu was of the view that the more cultural capital a student has, the better he or she would do in school (Bigelow 2007).

\section{Spaces of Inclusion, Care and Belonging}

The study indicated that there were significant spaces of inclusion, belonging and affirmation in the schooling context. Integral to such spaces were teachers, school gatherings, significant relationships, social networks and peer groups that contributed to the migrant learners experiencing the school system in a positive manner, and celebrated their power over adversities and vulnerabilities. Participants made particular mention of the school assembly - a space where they felt affirmed. Magnus from Zimbabwe explains a photo he took of the assembly area.

The assembly area is my favourite. It's a place where all of my efforts are paid off and my achievements can be shown. I always feel above all the negative comments and above of the people who would look down on me. It makes me proud of what I have achieved in school .... in class and even with sport ... because it's a place where the teachers tell the other students that we are examples to them, like my Afrikaans teacher ... she says she wants to take us and tell the whole school how well we do and that really makes me feel proud and motivates me. So I am focused and dedicated to doing well and my teachers really push me to be better (Photo narrative).

Suárez-Orozco et al. (2009) argue that there needs to be adequate support networks present in school contexts for immigrant students to feel included. Healthy relationships with peers, teachers, counsellors and other supportive 
adults in the schooling spaces are important to the participants in this study. In the focus group discussions, participants were in praise of certain teachers who were kind, caring of their well-being, and made them feel that they were valued in the schooling context. Magnus, 17 years old, Zimbabwe stated this.

Mrs N's class and Mr N are my parents at school so to say. Like I told you about the time when I was sick and when I got back to school, they got me medication that really helped me. In addition, Mrs $\mathrm{N}$ often pays for my school trips when I can't afford them. So my teachers really love and watch over me (Focus group interview).

He added:

... like my English teacher Mrs. G, she's very, very nice; she treats me like her own son (Focus group interview).

Thomas, 17 years old, Zimbabwe gave this account:

Well for me my Life Skills teacher like the first term this year, I passed but not as good as I wanted to, so then she called me and for like 10 minutes we had a discussion and she said that I can do better. And she even told me that if I wanted extra lessons, she would help me if she's free. I had thought she was just joking, that she was just trying to make me feel better. Sometimes she will come over to Pinetown to the library and give me some extra lessons - it was like most of the weekends. She used to tell me, 'You can be better and I mean top 3 students in the school ... and I want you to work harder each and every day ... you need to remember that you came to this country for a better life' (Focus group interview).

The participants made special mention of teachers at the school who are migrants, and the fact that these teachers were significant to their academic and social well-being. Ian and Alice talked about their physics teacher.

My physics class, it's the place I feel safe most around the school. Mr C. who is from Zimbabwe is supportive and really motivates me as well; he pushes me to do better. I actually know the safe places ...Mr 
C's and Mr R's classes are the areas that I feel really safe. So that's where I usually hang out. (Ian, 17 years old, Malawi) (Photo narrative).

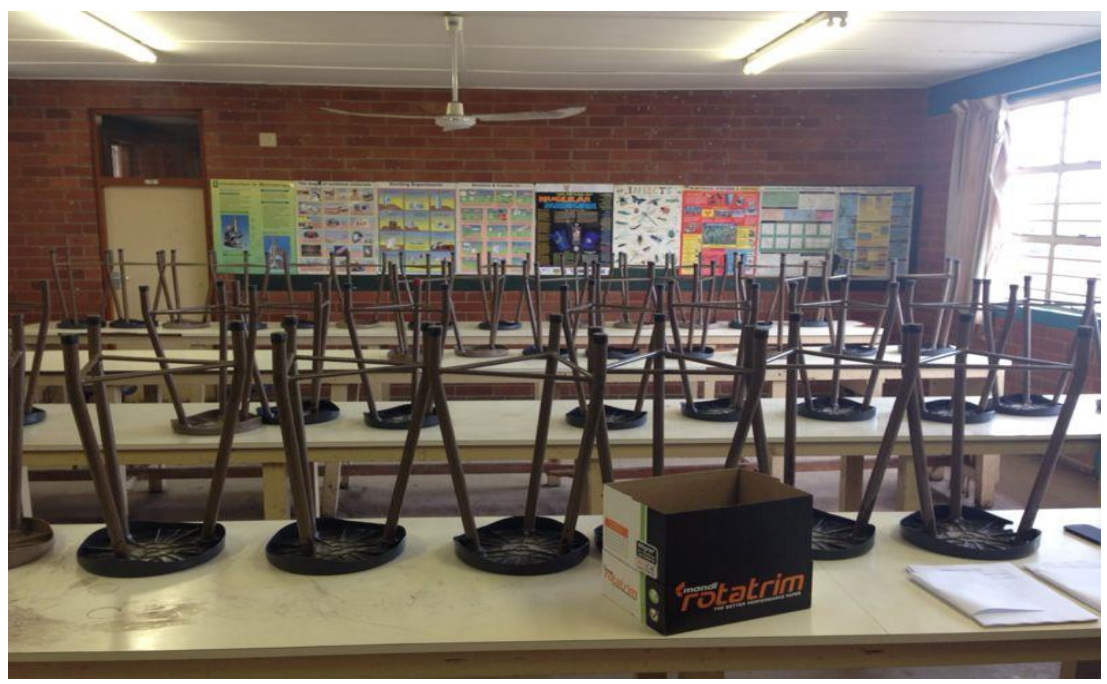

Figure 3: The classroom space

Supportive teachers, according to the learners, were caring and went beyond the call of duty. It is significant from the narratives that such teachers build a culture of support, respect, encouragement, motivation and caring to ensure positive schooling experiences for learners. It was evident from the narratives that the learners gravitate to spaces where they feel a sense of acceptance and belonging, as argued by Wells (2011).

The strong supportive network amongst migrants emerged in the narratives to the extent that they monitor and feel that they are accountable for the well-being of their migrant peers. Amanda, 18 years old, Zimbabwe offered the following insights.

There are some other ones here, the Malawians who have kinda [kind of] experienced a lot. Last year it was very tough and we had to help them, it was tough for them because they were just adjusting ... ja it was really tough for them. The other students called them names...it 
was really tough. They were lonely but they are in matric now (Amanda, Zimbabwe) (individual interview).

\section{Conclusion}

The data presented in this article are grounded in the narratives of seven migrant learners attending a secondary school in South Africa. The findings indicate that these learners face significant discrimination, prejudice and oppression, mainly from peers at school. The narratives exposed the xenophobic attitudes of certain South African learners in the schooling context. Studies suggest that such attitudes are reflective of their socialisation by parents, family and community, which are reproduced in schooling contexts. In the participants' narratives, it is noteworthy that teachers were portrayed as caring and supportive, and there was no evidence of teachers being agents of oppression. However, the data suggests that teachers are unaware of the discrimination and prejudice suffered by migrant learners from their peers, largely due to silence on the part of the migrant and South African learners. The study indicated that there are no programmes at the school aimed directly at fostering a positive and caring learning environment in which the rights of migrant learners are protected and valued. The study revealed that migrant learners use their own agentic resources and strategies to navigate oppression.

South Africa has ratified both the UN Convention on the Rights of the Child (United Nations 1989) and the African Charter on the Rights and Welfare of the Child (Organisation of African Unity (OAU) 1990). These instruments recognise the right of the child to quality education, and this pertains to all children in a country, irrespective of the nationality or legal status of the family. Similarly, the Bill of Rights of the South African Constitution endorses the right to quality education for all children, and places responsibility on government and its agencies such as schools to ensure that this right is upheld. The National Education Policy Act of 1996 and the South African Schools Act of 1994 go further to endorse the right of every learner to be protected against unfair discrimination on any grounds within the education system. The oppression experienced by the migrant learners in this study is contradictory to a high quality, rights-based education, free of discrimination which is guaranteed to all learners in South African policy and legislation. This makes it imperative that whole school development programmes, school leadership and teacher professional development interventions have a strong focus on 
issues of diversity, social justice and anti-racism (hooks 1994; Reygan \& Steyn 2017) to equip schools to confront oppression, disrupt its various faces, and address the unequal power dynamics that operate in schools and classrooms. This would require promoting critical conversations at all levels of the schooling system, and involving learners, teachers, school and education leaders, families and community. Further, programmes need to shift beyond constructing migrant learners as victims of oppression to enhancing and supporting their individual and collective agency and resilience.

The theoretical and conceptual framing of such interventions is critical. We argue for a social justice education framing to enable the reflexive examination of dominant discourses, values, beliefs and actions that perpetuate oppression. The framework 'Critical Diversity Literacy' (CDL) by Melissa Steyn (Steyn 2015) focusses on building educator competence in identifying and examining operations of power and oppression in schooling contexts. CDL referred to as 'reading practice' provides a set of analytic skills to enable teachers to identify, think about prejudice and discrimination in reflexive ways, act to disrupt social oppression (Reygan \& Steyn 2017), and build resiliency and agency amongst learners. The key goal should be to build schools that are safe, caring, inclusive and non-discriminatory spaces that promote rights awareness.

\section{References}

Adebayo, A.C. 2010. Education and Socio-Cultural Challenges of Immigrant Students in a School in South Africa. Masters dissertation, University of Pretoria.

Amnesty International 2019. What's the Difference between a Refugee and Asylum Seeker? London: Amnesty International.

Asanova, J. 2005. Educational Experiences of Immigrant Students from the

Former Soviet Union: A Case Study of an Ethnic School in Toronto.

Educational Studies 3, 2: 181 - 195.

https://doi.org/10.1080/03055690500095589

Bell, N. 2008. Ethics in Child Research: Rights, Reason and Responsibilities.

Children's Geographies 6, 1: 7 - 20.

https://doi.org/10.1080/14733280701791827

Bigelow, M. H. 2007. Social and Cultural Capital at School: The Case of a Somali Teenage Girl. 
http://www.theliteracyinstitute.org/projects/pdf/LESLLA\%20Research1. pdf

Bourdieu, P. \& J.C. Passeron 1977. Reproduction in Education, Society, Culture. Beverly Hills: Sage.

Cele, S. 2006. Communicating Place Methods for Understanding Children's Experience of Place. Sweden: Intellecta Docusys AB.

Chigeza, S., A. de Wet, V. Roos \& C. Vorster 2013. African Migrants' Experiences of Xenophobic Violence in South Africa: A Relational Approach. Journal of Psychology in Africa 23, 3: 501 -505.

Clandinin, J., D. Pushor \& A. Murray Orr 2007. Navigating Sites for Narrative Inquiry. Journal of Teacher Education 58, 1: 21 - 23.

https://doi.org/10.1177/0022487106296218

Connelly, F.M. \& D.J. Clandinin 1990. Stories of Experience and Narrative Inquiry. Educational Researcher 195: 2 - 14.

https://doi.org/10.3102/0013189X019005002

Crul, M., E. Schneider, F. Keskiner \& T. Lelie 2017. The Multiplier Effect: How the Accumulation of Cultural and Social Capital Explains Steep Upward Social Mobility of Children of Low-educated Immigrants. Ethnic and Racial Studies 40, 2: 321 - 338.

https://doi.org/10.1080/01419870.2017.1245431

Crush, J. \& G. Tawodzera 2011. Right to the Classroom: Educational Barriers for Zimbabweans in South Africa. Cape Town: IDASA.

http://samponline.org/wp-content/uploads/2016/10/Acrobat56.pdf

Daniels, D. 2018. Educating in Diverse Worlds: The Immigrant Somali Parent as a Strategic Partner of South African Education. In Walton, E. \& R. Osman (eds.): Teacher Education for Diversity: Conversations from the Global South. London: Routledge.

Darmody, M., D. Byrne \& F. McGinnity 2013. Cumulative Disadvantage? Educational Careers of Migrant Students in Irish Secondary Schools. Race, Ethnicity and Education 17, 1: 129 - 151.

https://doi.org/10.1080/13613324.2012.674021

De Gialdino, I.V. 2009. Ontological and Epistemological Foundations of Qualitative Research. Forum: Qualitative Social Research 10,2.

http://www.qualitative-

research.net/index.php/fqs/article/view/1299/3163

Denzin N.K. \& Y.S. Lincoln 2005. The SAGE Handbook of Qualitative Research. $3^{\text {rd }}$ Edition. London: Sage. 
Dryden-Peterson, S., N. Dahya \& E. Adelman 2017. Pathways to Educational Success among Refugees: Connecting Locally and Globally Situated Resources. American Educational Research Journal 5, 46: 1011 - 1047. https://doi.org/10.3102/0002831217714321

Fontana, A. \& J.H. Frey 2003. The Interview: From Structured Questions to Negotiated Text. In Denzin, N.K. \& Y.S. Lincoln (eds.): Collecting and Interpreting Qualitative Materials. Thousand Oaks: Sage.

Gifford, S.M., C. Bakopanos, I. Kaplan \& I. Correa-Velez 2007. Meaning or Measurement? Researching the Social Contexts of Health and Settlement among Newly Arrived Refugee Youth in Melbourne, Australia. Journal of Refugee Studies 20, 3: 414 - 440. https://doi.org/10.1093/jrs/fem004

Golombek, P.R. \& K.E. Johnson 2004. Narrative Inquiry as a Mediational Space: Examining Emotional and Cognitive Dissonance in Secondlanguage Teachers' Development. Teachers and Teaching: Theory and Practice 10, 3: 307 - 326. https://doi.org/10.1080/1354060042000204388 Hemson, C. 2011. Fresh Grounds: African Migrants in a South African Primary School. Southern African Review of Education 17: 65 - 85.

Hlatshwayo. M. \& S. Vally 2014. Violence, Resilience and Solidarity: The Right to Education for Child Migrants in South Africa. School Psychology International 35, 3: 266 - 279.

https://doi.org/10.1177/0143034313511004

Holloway, S. \& G. Valentine 2000. Spatiality and the New Social Studies of Childhood. Sociology 34: 763 - 783.

https://doi.org/10.1017/S0038038500000468

hooks, b. 1994. Teaching to Transgress: Education as the Practice of Freedom. New York: Routledge.

Hunter, S.V. 2010. Analysing and Representing Narrative Data: The Long and Winding Road. Current Narratives 2: 44 - 54.

http://ro.uow.edu.au/currentnarratives/vol1/iss $2 / 5$

Isseri, S., N. Muthukrishna \& S. Philpott 2018. Immigrant Children's Geographies of Schooling Experiences in South Africa. Educational Research for Social Change 7, 2: 39 - 56.

https://doi.org/10.17159/2221-4070/2018/v7i2a3

Jacobs, S. \& A. Harley 2008. Finding Voice: The Photovoice Method of Data Collection in HIV and AIDS-related Research, Journal of Psychology in Africa 18, 3: 431 - 438.

https://doi.org/10.1080/14330237.2008.10820219 
James, A. \& Prout, A. 1997. Constructing and Reconstructing Childhood: Contemporary Issues in the Sociological Study of Childhood. London: Falmer.

Jeffrey, C. 2010. Geographies of Children and Youth: Eroding Maps of Life.

Progress in Human Geography 34, 4: 496 - 505.

https://doi.org/10.1177/0309132509348533

Kamuangu, G. 2007. Learning and Forgetting: The Use of Languages in the Diaspora. The International Journal of Learning 14, 4: 49 - 52.

https://doi.org/10.18848/1447-9494/CGP/v14i04/45310

Kruger, D. \& R. Osman 2010. The Phenomenon of Xenophobia as Experienced by Immigrant Learners in Johannesburg Inner City Schools. Perspectives in Education 28, 4: 53 - 60.

Maduray, K. 2016. The Geographies of Schooling Spaces for Immigrant Children: Vulnerability, Belonging, Exclusion and Power. Master's thesis, University of KwaZulu-Natal.

McGovern, M. \& D. Devine 2015. The Care Worlds of Migrant Children Exploring Inter-generational Dynamics of Love, Care and Solidarity Across Home and School. Childhood 23, 1: 37 - 52.

https://doi.org/10.1177/0907568215579734

Meda, L. 2017. Refugee Learner Experiences: A Case Study of Zimbabwean Refugee Children. Hamburg: Anchor Academic Publishing.

Morojele, P. \& N. Muthukrishna 2012. The Journey to School: Space, Geography and Experiences of Rural Children. Perspectives in Education 30, 1: 90 - 100.

Moskal, M. 2014. Language and Cultural Capital in School Experience of Polish Children in Scotland. Race, Ethnicity and Education. 19, 1:141 160. https://doi.org/10.1080/13613324.2014.911167

Ngcamu, B.S. \& E. Mantzaris 2019. Xenophobic Violence and Criminality in the KwaZulu-Natal Townships. The Journal of Transdisciplinary Research in South Africa 15, 1. https://doi.org/10.4102/td.v15i1.606

Newman, M., A. Woodcock \& P. Dunham 2006. Playtime in the Borderlands: Children's Representations of School, Gender and Bullying through Photographs and Interviews. Children's Geographies 4, 3: 289 - 302.

https://doi.org/10.1080/14733280601005617

Nnadozie, J.I. 2010. Exploring the Schooling Experience of Migrant Children from the Democratic Republic of Congo in South Africa. Doctoral dissertation, University of KwaZulu-Natal. 
Nithi Muthukrishna, Kubendri Maduray \& Susan Philpott

Organisation of African Unity (OAU). 1990. African Charter on the Rights and Welfare of the Child. Addis Ababa: OAU.

Osman, R. 2009. The Phenomenon of Xenophobia as Experienced by Immigrant Learners in Inner City Schools of Johannesburg. Master's dissertation, University of South Africa.

Republic of South Africa 1998. Refugees Act, Act 130 of 1998.

http://www.home-affairs.gov.za/PDF/Acts/Refugees\%20Act130.pdf

Republic of South Africa 1999. White Paper on International Migration,

Pretoria, Government Gazette No. 19920.

http://www.info.gov.za/whitepapers/1999.

Republic of South Africa 1994. South African Schools Act, No. 84. Pretoria:

Government Printer.

Republic of South Africa 1996. Constitution of the Republic of South Africa.

Pretoria: Government Printer.

Republic of South Africa 2002. Immigration Act, No. 13 of 2002. Pretoria:

Government Printer.

Republic of South Africa. 2004. Immigration Amendment, Act No. 19 of 2004.

Pretoria: Government Printer.

Reygan, F. \& M. Steyn 2017. Diversity in Basic Education in South Africa:

Intersectionality and Critical Diversity Literacy. Africa Education Review 14, 2: 68 - 81. https://doi.org/10.1080/18146627.2017.1280374

Seamon, D. \& J. Sowers 2008. Place and Placelessness (1976): Edward Relph.

In Hubbard, P., R. Kitchen \& G. Vallentine (eds.): Key Texts in Human

Geography. London: Sage.

Suárez-Orozco, C., A. Pimentel \& M. Martin 2009. The Significance of

Relationships: Academic Engagement and Achievement among

Newcomer Immigrant Youth. Teachers College Record 11, 3: 712 - 749.

Steyn, M. 2015. Critical Diversity Literacy: Essentials for Twenty-first

Century. In Vertovec, S. (ed.): Routledge Handbook of Diversity Studies.

New York: Routledge.

UN General Assembly July, 1951. Convention Relating to the Status of Refugees. Geneva: United Nations.

https://www.refworld.org/docid/3be01b964.html

United Nations. 1989. The Convention on the Rights of the Child. New York: United Nations.

Van der Burgt, D. 2015. Spatial Avoidance or Spatial Confidence? Young People's Agency in the Active Negotiation of Risk and Safety in Public 
Space. Children's Geographies 13, 2:181 - 195.

https://doi.org/10.1080/14733285.2013.828455

Van Ingen, C.V. \& F. Halas 2006. Claiming Space: Aboriginal Students within

School Landscapes. Children's Geographies 4, 3: 379 - 398.

https://doi.org/10.1080/14733280601005856

Van Lennep, T. 2019. The South African Migration Policy Landscape (II). https://www.politicsweb.co.za/opinion/migration-ii-the-south-africanmigration-policy-la

Vandeyar, S. 2012. Immigrant Students' Shifting Identifications in South African Schools. International Journal of Educational Development 32: 232 - 240. https://doi.org/10.1016/j.ijedudev.2011.03.006

Vandeyar, S. \& T. Vandeyar 2011. Articulating Cultures: Socio-cultural Experiences of Black Female Immigrant Students in South African schools. Gender \& Behaviour 9, 2: 4161 - 4188.

https://doi.org/10.4314/gab.v9i2.72190

Wells, K. 2011. The Strength of Weak Ties: The Social Networks of Young Separated Asylum Seekers and Refugees in London. Children's Geographies 9, 3 - 4: 319 - 329.

https://doi.org/10.1080/14733285.2011.590710

Wengraf, T. 2006. Qualitative Research Interviewing. Thousand Oaks: Sage.

Yu, K. \& B. Shandu 2017. Overcoming Language Barriers: Lessons Learnt from Migrant Children. Perspectives in Education 35,1: 157 - 170. http://dx.doi.org/10.18820/2519593X/pie

Nithi Muthukrishna

Professor Emeritus

School of Education University of KwaZulu-Natal Durban muthukri@ukzn.ac.za

Kubendri Maduray Postgraduate student School of Education University of KwaZulu-Natal Durban vaneshree.maduray@yahoo.com 
Nithi Muthukrishna, Kubendri Maduray \& Susan Philpott

Susan Philpott

Post-doctoral scholar

School of Education

University of KwaZulu-Natal

Durban

philpottsue@gmail.com 